\title{
L2 Fossilization: A Competence or a Performance Phenomenon
}

\author{
Christo Moskovsky ${ }^{*}$ and Silvia Ratcheva
}

The University of Newcastle, NSW, Australia

\begin{abstract}
The study reported here examined the question whether fossilization occurs as a result of competence deficiencies or is a function of processing constraints, i.e., a feature of performance. To address this issue, we first collected longitudinal data (2 years apart) from an adult second language (L2) learner of English. Error analysis conducted on our subject's L2 output revealed features that are consistent with the occurrence of fossilization: steady below norm levels of grammatical accuracy, fluctuation between correct and incorrect usage of the same structure, and backsliding. Next we used a grammaticality judgement (GJ) task to examine our subject's intuitions about the English article - the most pervasive error in his output; we also administered the same GJ task to eight native speaker controls. The analysis of the data from the grammaticality judgement task showed a clear mismatch between our subject's intuitions about article usage and those of the controls, suggesting that fossilization is most likely a competence phenomenon.
\end{abstract}

Keywords: Backsliding, competence/performance, fossilization, fluctuation.

\section{[F]ossilization has become widely accepted as a psychologically real phenomenon of considerable theoretical and practical importance.}

(Long, 2003)

\section{INTRODUCTION}

In the field of second/foreign language (L2) teaching/ learning it is widely recognized that for the vast majority of adult L2 learners the learning process stops (well) before the learner has attained native levels of competence in the target language (TL). It is noteworthy that this can often occur in situations in which conditions for learning remain favorable: the learner has the cognitive capacity to learn, $\mathrm{s} /$ he possesses good motivational levels, and continues to receive sufficient amounts of relevant TL input (including corrective feedback). Nemser (1971) described this phenomenon as a 'stabilized intermediate system', while Selinker (1972) coined the term 'fossilization' and defined it as "the permanent cessation of IL learning $[\mathrm{sic}]$ before the learner has attained target language norms at all levels of linguistic structure and in all discourse domains in spite of the learner's positive ability, opportunity or motivation to learn or acculturate into target society" (Selinker \& Lamendella, 1978). Fossilization is "a founding concept in second language acquisition (SLA) research" (Han, 2013).

Fossilization is one of the most pervasive, yet least well understood, phenomena in adult L2 learning-despite the substantial research effort devoted to it. In a state-of-the-art article, Han (2013) evaluates fossilization research conducted over the last forty years and points to the advances made in conceptualization and methodology, and discusses the emerging predictive and explanatory power of

*Address correspondence to this author at the School of Humanities and Social Science, The University of Newcastle, Callaghan, NSW2308, Australia: Tel: (61+2) 4921 5163; Fax: (61+2) 4921 7170;

E-mail: Christo.Moskovsky@newcastle.edu.au different theories. Han advocates her Selective Fossilization Hypothesis (SFH) and by re-examining previous findings within her new framework arrives at four generalizations:

\section{Fossilization is selective}

2. Fossilization affects the acquisition of TL structures encoding variable form, meaning, and function (discourse pragmatics) relations.

3. Fossilization is inspired by an L1-relativised mind, induced or reinforced by L2 input attributes.

4. Fossilization is most evident in spontaneous production in which the learner engages in manufacturing his own meaning and linguistic expression (Han, 2013).

Although the above generalizations seem to narrow down the array of factors that were initially thought to pertain to fossilization, it is clear that defining the phenomenon as a product or a process, or both, remains as difficult as ever. Generalization 3 is of particular interest since it seems to offer a plausible account of the cognitive mechanisms involved in fossilization and the factors causing it. The invocation of Slobin's Thinking-for-Speaking (TFS) hypothesis (a theory of linguistic relativism; hence 'an L1relativised mind') in the Selective Fossilization Hypothesis (Han, 2013) suggests that the search for an explanation of SLA-specific phenomena, among which fossilization undeniably holds a central position, can benefit from breaking from the mould of Chomskyan linguistics and from venturing beyond the theoretical bounds of principles and parameters. Chomsky is well known for introducing the dichotomy between competence (mental representations of language) and performance (language in use) and the idea that linguists should first and foremost describe competence, 
not performance. The study of fossilization automatically falls in the performance side of the Chomskyan framework - as generalizations 2 and 4 suggest, fossilization concerns discourse pragmatic relations and is validated in spontaneous language production. Thus, we began our investigation with the assumption that fossilization is a performance based phenomenon.

\section{DESCRIBING FOSSILIZATION}

Fossilization as an interlanguage (IL) phenomenon has been found to involve a range of rather special features which make it extremely difficult to describe and explain theoretically. In view of that, it is not surprising that it has taken researchers this long to begin to identify possible causal variables. In the first place, there seems to be no apparent reason for the discontinuation of L2 learning to occur: as pointed out above, fossilization can take place despite the continued availability of favourable conditions for learning. Another frequently attested property of fossilization which has presented serious problems for L2 acquisition theory is described by Han $(1998,2000)$ as 'stabilized variation over time'; Long (2003) uses the term 'fluctuation' to refer to the same phenomenon. It reflects the widely established fact that 'fossilized' L2 learners may use the same TL structure accurately some of the time, and inaccurately the rest of the time. A related property of fossilization is 'backsliding': fossilized learners' L2 performance accuracy may in fact drop over time. As mentioned in the introduction, there is now an agreement among fossilization researchers that behavioral manifestations of fossilization, such as variation and backsliding, occur only with some linguistic features; in other words, fossilization is not global, but selective and predictions can now be made as to which specific features are likely to fossilize in an L2 learner's IL. What makes fossilized IL performance particularly hard to account for is that this fluctuation commonly takes place at the level of the token, rather than the type, and also seems to be sensitive to discourse domains or contexts (Douglas \& Selinker, 1985; Selinker \& Lamandella, 1978). It is unclear why fossilization often manifests itself with regard to members of the same class (i.e., the tokens), but not the class as a whole (i.e., the type), and it seems particularly challenging to offer a consistent theoretical account of such facts, much more so than if this variation took place at the level of the type.

\section{PUTATIVE CAUSES OF FOSSILIZATION}

To the extent that fossilization can be assumed to exist as an IL characteristic, its underlying causes until recently remained unclear even though various studies had hypothesized one or more factors as responsible for causing fossilization (Long, 2003; Han, 2013). Some of these, such as lack of desire to acculturate, communicative pressure (i.e., pressure to start using the L2 communicatively before the L2 learner is psychologically and/or cognitively ready), lack of learning opportunity and/or lack of relevant negative feedback have been seen as contributing to fossilization, but cannot be regarded, individually or together, as its ultimate cause, because fossilization has been found to occur even where these factors are absent.

Other factors that have been found to be relevant to fossilization include 'transfer' and 'age'. In relation to the for- mer, literature on fossilization indicates that at least some fossilized IL structures can be attributed to the influence of the L2 learner's native language (see Han, among many others). However, in view of the fact that transfer is an IL phenomenon common to all adult L2 learners (fossilized and unfossilized alike), it is an unlikely candidate as the ultimate cause of fossilization on its own. As Han (2013) concludes, it is the interaction between L1 transfer and the attributes of the L2 input that is the likely source of fossilization.

As regards the role of age, given favorable conditions, prepubescent L2 learners do not fossilize. The majority of adult L2 learners however are vulnerable to fossilization at one point or another of their IL development; therefore age must be a relevant factor. It is nevertheless impossible to explain fossilization in terms of the decline in cognitive ability associated with more advanced age (Bosman \& Charness, 1992; Denney, 1990), because in healthy individuals this decline does not lead to a complete loss of the ability to learn. Furthermore, fossilization has sometimes been found to affect individuals whose age can hardly be described as 'advanced' (e.g., learners in their 30s). That said, biocognitive maturity and the influence of L1 are recognized as the "the two factors broadly predisposing learners across the board to fossilization" (Han, 2013).

Long (2003) promotes the view that the most plausible reason for the occurrence of fossilization is loss of sensitivity to TL input and the related ability to notice the mismatch between TL input and L2 output. This ability, according to Carroll (2001), is the driving force behind (second) language acquisition: the existence of a mismatch between input and output drives learning in the sense that it provokes, in the interim grammar of the L2 learner, the formation of new grammatical categories and/or the restructuring of existing categories. When such a mismatch continues to exist, but the learner is no longer aware of it, provision of new input does not trigger any learning, which is arguably the point at which fossilization occurs. This is in accord with Gass's (1997) view that "fossilization occurs when new (correct) input fails to have an impact on the learner's grammar."

Empirically, there seems to be some support for the idea that sensitivity to input is related to fossilization, as at least some of the studies dealing with fossilization report that their (presumably fossilized) subjects displayed relatively low sensitivity to input. Long argues that the relative perceptual saliency of input structures is also a factor: perceptually less salient linguistic features are more likely to fossilize than otherwise. Among structures which are relatively less perceptually salient and therefore arguably prone to fossilization, there are, according to Todeva (1992), three categories which are especially "at risk": (i) structures with an opaque form-function relationship (e.g., articles); (ii) semiproductive rules (i.e., ones which do not apply to the majority of members of a class, e.g., negative prefixation in English); and (iii) units of arbitrary nature (e.g., prepositions, collocations; gender assignment in languages like German and Bulgarian).

Without denying the importance of sensitivity to input in relation to L2 acquisition, and the role that its loss may play in the onset of fossilization, an explanation of what causes fossilization would have to go further than that, and would have to also explain how and/or why this loss of sensitivity 
to input occurs. Admittedly, the role of perceptual saliency must clearly be taken into account, but again it cannot by itself explain fossilization, because it is not the case that only less salient TL grammatical features fossilize-even TL structures with a very transparent form-function relationship (e.g., the English plural) can be affected by fossilization. It also needs to be pointed out that neither sensitivity to input nor perceptual saliency can explain why the attested fluctuation in fossilized L2 performance takes place at the level of the token, not the type.

Han's Selective Fossilization Hypothesis (SFH) takes a slightly different angle. Reminiscent of Eckman's (1977) Markedness Differential Hypothesis, Han (2013) proposes an interaction between first language (L1) markedness and L2 input robustness as the two key variables in demarcating four zones; the fossilization zone is demarcated by unmarked L1 usage and non-robust L2 input. The fossilization of a linguistic form then is, according to Han, "largely a function of the interaction of an unmarked usage in the L1 and a piece of non-robust input providing weak evidence for some TL usage" (2013). When it comes to L2 production, the learner faces processing difficulties. Here is where the Thinking-forSpeaking (TFS) hypothesis is invoked-grammatical forms encode concepts such as number, definiteness and the like; the encoding of these in a second language may require restructuring of the L2 learner's conceptual system and the likelihood of this happening is small. Thus, in the production of messages, the conceptualizer packages messages in L1 and the formulator encodes these in L2 grammar and phonology. We see results from our investigation as a possible elaboration on this view.

\section{RESEARCHING FOSSILIZATION: METHODOLOGI- CAL ISSUES}

Some fossilization studies are cross-sectional by design and their findings have been judged to be unreliable sinceas Long (2003) points out-it is impossible to ascertain whether IL development has ceased on the basis of a single diagnostic event, regardless of a participant's length of residence in the TL country. Other fossilization studies are longitudinal by design and involve collecting naturalistic and/or experimental data from L2 learners/users at two or more points in time (see Long, 2003, for review). A major issue with these studies has been the adequacy of the length of time between the elicitation events; Selinker has proposed that two to five years may be sufficient (Selinker \& Lamendella, 1978; Selinker, 1991).

Important as length of time appears to be, Long (2003) argues that the worth of fossilization claims should be judged against a combination of factors; according to him, selecting appropriate respondents constitutes a major one among them. Long lists numerous studies that have failed to include data on their participants' abilities, motivation or opportunities to learn. Level of L2 language proficiency appears to be a prominent background characteristic since "all other things being equal, a study involving advanced learners is more likely to be successful in identifying persistent errors, simply because errors remaining in the ILs of advanced learners are more likely to be potentially permanent problems than errors found in the ILs of less proficient learners, which will include a greater variety and number, but many that will disappear with increasing proficiency" (Long, 2003).

What constitutes relevant data in fossilization research has also come under scrutiny. The current understanding tends to emphasize meaning and usage - rather than linguistic form - as data for fossilization studies; form is only one aspect of the target norm. Eclectic approaches to data collection are recommended: naturalistic output, clinical elicitation, and grammaticality judgement (GJ) tasks. In cases where spontaneous production of L2 cannot be recorded, grammaticality judgment (GJ) methodology has been advocated as an alternative method of investigating fossilization (Han, 2006). Studies utilizing this methodology found that L2 learners lacked intuition about the grammaticality status of the structures under investigation or - put differently-L2 learners' grammatical knowledge was indeterminate; importantly, so was the native speakers' knowledge (Han, 2006). These findings initially cast doubt on the reliability of GJ as a source of data for the study of fossilization. Recently another view has emerged suggesting that indeterminacy does not reside in the nature of the task but in the nature of the interlanguage itself: "What if indeterminacy is the norm, rather than a transient feature, of the interlanguage?" asks Han (2006). Also, considering that fossilization is TL centered, on the one hand, and that natural languages are dynamic systems, on the other, what if "there is no finite uniformity to conform to" (Larsen-Freeman, 2006).

In our view, Han's (2006) longitudinal study is the only one to have properly addressed the issues identified above. Her two participants were of the appropriate kind - advanced users of English who had resided in the TL country for five years at the commencement of the research, held doctoral degrees and worked as research fellows at a university. She collected two types of data-naturalistic production and grammaticality judgments, over a seven-year period. She also recruited one native speaker participant to serve as a control on the GJ test. It should be noted, however, that Han and the researchers whose work she reviews have used GJ tasks solely to test their reliability as fossilization data-that is, the perspective taken was purely methodological. The opinions on this issue of GJ reliability remain divided.

\section{THE PRESENT STUDY}

As we pointed out at the beginning, our zero hypothesis was that fossilization is a performance, rather than a competence, phenomenon. The persistent fluctuation between correct and incorrect usage of the same TL structure, which is considered a prelude to fossilization, seems to provide strong support for such a view. Suppose that a fossilized learner applies a TL rule correctly $50 \%$ of the time, which was in fact the case with Long's (2003) subject in her use of the past tense in English. It seems inconceivable that such a consistent application of the rule does not reflect an internalized rule, a rule which is a part of the learner's (interim) L2 grammar. If this is indeed the case, then the fluctuation between correct and incorrect use occurs not as a result of imperfect knowledge of the TL rule (i.e., a competence deficiency), but rather as a result of imperfect processing: informally, the correct grammatical form seems to get lost somewhere on the way between the speaker's competence and her performance. Some support for this idea comes from Lar- 
diere's $(1998,2000)$ longitudinal study of her subject Patty, providing evidence that (some) L2 learners may lack the complex procedures for mapping abstract syntactic features to specific morpho-phonological forms.

Since the Chomskyan framework seems to dominate much of the work in the field of SLA, it is not surprising that the question of whether fossilization reflects deficiencies in the internalized linguistic system of the L2, or whether it reflects some processing limitations which affect the productive use of this internalized linguistic system has received very little attention. Long (2003) acknowledges that "a processing dimension is needed, one which combines cognitive factors with input characteristics," but pursues this no further. It's only quite recently that Han (2013) has offered a truly processing account of fossilization (see the section on Putative Causes of Fossilization above).

The current study was specifically designed to shed light on the competence vs. performance dimension of fossilization.

The study's principal objectives were: 1) To establish empirically a case of an L2 learner of English, whose accuracy levels of L2 performance have remained stable below norm for a relatively long period of time: in this case 24 months, and 2) To identify an L2 structure which involves fluctuation in the subject's L2 performance and establish whether this fluctuation reflects competence deficiencies or language processing (i.e., performance) constraints.

\section{METHODOLOGY}

\section{Design}

The present study is a case study of one individual and is longitudinal and descriptive by design. Our participant sample size is consistent with longitudinal case studies of this type examining developmental aspects of language acquisition (first, second, bilingual, etc.), which commonly involve very small participant numbers, quite often just one. The rationale is that, with language being such a fundamental biologically determined skill, what holds for a single normal speaker is likely to hold for every normal speaker. In fact, some of the best known and most highly regarded longitudinal studies on L2 fossilization have only involved one or two participants (see Han, Lardiere, Long, among others).

The current investigation builds on and extends Han's research methodology and uses it in a novel way to achieve its main objective - namely, to establish whether fossilization is performance or competence based. In the first place we identified an adult L2 learner whose background characteristics suggested high degree of suitability for participation in fossilization research in terms of length of residence, cognitive capacity, learning conditions, motivation, exposure to input and opportunity to engage in authentic communication. This participant's recruitment took place as part of a larger scale project investigating issues of L2 fossilization in Australian residents from a non-English speaking background. Then we collected two spontaneous-production language samples from that participant (24 months apart-meeting Selinker's minimum length-of-time requirement) and conducted error analysis on the data. Thus, we were able to establish the unit of fossilization for the present study at a contextualized, discourse level. Next our participant completed a grammatical- ity judgement (GJ) task in order to test our participant's intuitions and knowledge about the grammatical feature identified at the discourse level. Finally, the subject's judgements on the GJ task were compared to those of eight English native speaker (NS) controls.

\section{The Participant}

Our participant, pseudo-named Alex, is a highly educated native speaker of Russian with a $\mathrm{PhD}$ in physics, who at the time of the project presented here was working as a researcher in the university sector in Australia. His initial age of exposure to English was at 12 years of age, i.e., around the hypothesized closure-off of the critical period. His length of residence in an English-speaking environment had been, by the time of the first collection of data, around 8 years. His performance on both occasions demonstrated a highly fluent and confident use of spoken English with relatively few grammatical errors. Alex in many ways constituted the ideal subject for a fossilization study: he obviously had a very high level of cognitive ability, he had had plenty of continuous formal and informal exposure to English, he was still relatively young (in his late 30 s at the time the data collection started), and his responses to the questionnaire ${ }^{1}$ which we used to recruit participants for the original larger scale study indicated a keen desire to improve his competence in English further.

\section{Data Collection and Analysis}

Language samples were collected from Alex on two separate occasions, 24 months apart. Each of the samples involved spontaneous oral performance in the TL by Alex on topics of his choice. Alex chose to talk about a one-week vacation he had taken in Australia shortly before time 1 (T1) of the data collection, and about a one-week overseas trip taken shortly before time 2 (T2). The participant spoke for approximately 10 minutes each time with as little interruption by the researcher as possible. Both talks were audio-recorded. The two samples were then transcribed by one of the researchers and checked for accuracy by the other. The two transcripts were of similar length, with T1 transcript word count of 1359 and T2 transcript of 1106 words. The transcripts were then subjected to error analysis. The analysis revealed a range of erroneous TL structures in Alex's performance, but we chose to focus on just one of them, the English articles. Han (2013) states that "the English articles the/a present a universal challenge to learners from the various L1 backgrounds lacking such features." Given that Alex's native language, Russian, has no articles, it was of little surprise that article use happened to be the single most pervasive error in the two transcripts. In order to determine correct and incorrect suppliance, as well as correct and incorrect non-suppliance, of indefinite and definite articles, we counted in all nominal structures (including proper names) containing a potential specifier position, either empty or

\footnotetext{
${ }^{1}$ This initial questionnaire contained items targeting relevant demographic information (e.g., native language, level of education, current occupation, age of initial exposure to English, nature and intensity of exposure to English), as well as items tapping potential participants' motivation to improve their level of English. One of the purposes of the questionnaire was to screen out potential participants who for some reason could be unsuitable for our project, e.g., because of early initial exposure to the L2 or lack of sufficient motivation.
} 
filled with an article. Non-article determiners were not considered. Thus nominals like 'traffic', 'bushwalking', 'Australia', 'New York', etc. were treated as cases of correct nonsuppliance of the article, while nominals like '(an) English speaking family', '(a) nice place', etc. were treated as incorrect non-suppliance, and respectively counted as errors.

Following the analysis of the two transcripts, we constructed a grammaticality judgement task consisting of 35 sentences (see Appendix). Because these were decontextualized sentences, we needed to ensure that the (un) grammatical use of articles was fairly uncontroversial; hence, the task was piloted on two native speakers of English: both highly educated, one of them a linguistics lecturer. Based on their feedback, some of the items of the grammaticality judgement task were slightly amended. Of the 35 sentences in the grammaticality judgement task 30 targeted article use, while the other five (\#\# 4, 8, 22, 30, 32) contained other (nonarticle) ungrammatical structures, and were used as 'distractors' - the rationale was to try and avoid alerting the subject that article use was specifically targeted, which would have had a contaminating effect on the collected data. These five distractors were not considered in the analysis of the data derived through the grammaticality judgement task. Of the 30 sentences targeting articles, 15 contained a single article error, while the rest were grammatically correct. Five of the ungrammatical sentences (\#\# 2, 7, 19, 25, 29) involved incorrect suppliance of either the indefinite or the definite article, while the remaining ungrammatical sentences (\#\# 3, 9, $10,12,13,15,23,26,34,35)$ involved incorrect nonsuppliance of either the indefinite or the definite article. The two pilot participants were instructed not only to identify the ungrammatical sentences, but also to provide a grammatical alternative for each. This was used as a safeguard to ensure that ungrammatical sentences were identified for the right reason. The task was then prepared for administration in electronic format in which a drop-down menu with the options 'grammatical' and 'ungrammatical' was inserted to the right of each sentence.

In order to be able to evaluate Alex's grammaticality judgements of article use, we administered the same grammaticality judgement task to eight native speakers, in addition to the two involved in the pilot. This control group of eight native speakers formed a convenience sample - they were all $\mathrm{PhD}$ students at the university where the study was conducted; importantly, they were all of comparable socioeducation status as Alex's.

\section{RESULTS}

\section{Naturalistic Production Data}

Table 1 below summarizes Alex's oral performance on selected grammatical items at time 1 (T1) and time 2 (T2) of the data collection.

As the numbers in the table show, there does not appear to be much of a difference between time 1 and time 2 in the participant's ungrammatical use of tense, aspect, and auxiliaries and copulas. If anything, there seems to be a slight improvement, suggesting that these areas of Alex's interlanguage might be undergoing development towards the TL norm. However, the difference in the correct and incorrect use of the article between $\mathrm{T} 1$ and $\mathrm{T} 2$ is strikingly obvious. In transcript 1 we counted 191 nominal phrases of which 111 did not require article suppliance, 42 required the use of the definite article, and 38 required the use of the indefinite article. The numbers in the column headed with T1 (the second column) show that Alex was correct in not supplying the article in 91 and incorrect in 20 out of the 111 nominal phrases that did not require article suppliance ( $81.98 \%$ and $18.02 \%$, respectively). He used the definite article correctly in 30 and incorrectly in 12 out of the 42 nominal phrases that required the use of the definite article (70.83\% and $29.17 \%$, respectively). As far as the indefinite article, he was correct in 29 and incorrect in 9 out of the 38 phrases that required its use $(76.32 \%$ and $23.68 \%$, respectively). Overall at $\mathrm{T} 1$ the number of correct uses of the article (150 out of a possible 191 or $78.53 \%$ ) was obviously by far greater (between 2 and 4 times) than the number of incorrect use (41 or 21.47).

In transcript 2 we counted 200 nominal phrases of which 101 did not require article suppliance, 57 required the use of the definite article, and 42 required the use of the indefinite article. The numbers in the column headed with T2 show that Alex was correct in not supplying the article in 57 and incorrect in 44 out of the 101 nominal phrases that did not require article suppliance $(56.44 \%$ and $43.56 \%$, respectively). He used the definite article correctly in 37 and incorrectly in 20 out of the 57 phrases that required the use of the definite article $(64.91 \%$ and $35.09 \%$, respectively). Finally, he used the indefinite article correctly in 17 and incorrectly in 25 out of the nominal phrases that required its use $(40.48 \%$ and $59.52 \%$, respectively). Overall at T2 the correct and incorrect uses of the articles were more balanced (55.5\% and $44.5 \%$, respectively). The percentages in bold in the rows headed with "Total" clearly show a drop in correct use of articles from $78.53 \%$ at $\mathrm{T} 1$ to $55.5 \%$ at $\mathrm{T} 2$ and an increase in incorrect use from $21.47 \%$ at $\mathrm{T} 1$ to $44.5 \%$ at $\mathrm{T} 2$. These results seem to constitute evidence of 'backsliding' in relation to Alex's IL article system; as Han points out, backsliding is identified by some as the "prime phenomenological manifestation of fossilization" (2004b, p. 17). Despite most favourable conditions for L2 acquisition, our participant's performance on the target-like use of articles had deteriorated over the two-year period.

\section{Grammaticality Judgment Task}

In the second component of the research we conducted a grammaticality judgement task targeting the types of errors that we found in the subject's own L2 output. The basic objective was to tap into the subject's L2 intuitions and establish whether the article errors reflect competence or performance deficiencies. This component of the research is in many ways much more interesting and significant, not least because it addresses an issue of substantial theoretical importance which, to the best of our knowledge, has not been tackled in previous fossilization research. The rationale was that if article errors occurred as a result of performance deficiencies, the subject would have no problems distinguishing between grammatical and ungrammatical sentences. Alternatively, failure to do so would indicate that the article errors are caused by competence deficiencies.

Table 2 below provides a comparative summary of the grammaticality judgements of Alex and the native speaker control group. 
Table 1. Participant's performance on selected grammatical items at time 1 and time 2 .

\begin{tabular}{|c|c|c|}
\hline Grammatical Item & $\begin{array}{l}\text { T1 (14-10-2005) } \\
\text { Frequency }\end{array}$ & $\begin{array}{c}\text { T2 (01-11-2007) } \\
\text { Frequency }\end{array}$ \\
\hline Tense & 5 wrong & 5 wrong \\
\hline Aspect & 3 wrong & 1 wrong \\
\hline Auxiliary and Copula & 4 wrong & 3 wrong \\
\hline \multicolumn{3}{|l|}{ Article Correct: } \\
\hline Non-suppliance & $81.98 \%(91 / 111)$ & $56.44 \%(57 / 101)$ \\
\hline Definite & $70.83 \%(30 / 42)$ & $64.91 \%(37 / 57)$ \\
\hline Indefinite & $76.32 \%(29 / 38)$ & $40.48 \%(17 / 42)$ \\
\hline Total & $\mathbf{7 8 . 5 3 \%}(150 / 191)$ & $\mathbf{5 5 . 5 \%}(111 / 200)$ \\
\hline Definite & $29.17 \%(12 / 42)$ & $35.09 \%(20 / 57)$ \\
\hline Indefinite & $23.68 \%(9 / 38)$ & $59.52 \%(25 / 42)$ \\
\hline Total & $21.47 \%(41 / 191)$ & $44.5(89 / 200)$ \\
\hline
\end{tabular}

Table 2. Frequency of failure to recognize ungrammatical sentences.

\begin{tabular}{|c|c|c|c|}
\hline 2 & Taking a leave seemed in theory appropriate at this point. & $2 *$ & $\mathrm{X}$ \\
\hline 7 & She thought that the orange dress was too bright and might lack the dignity. & & \\
\hline 12 & A thin layer of frost covered_ hardened ground. & $1^{*}$ & \\
\hline 13 & She had forgotten how nice it was, after so long_interval. & & $\mathrm{X}(?)$ \\
\hline 15 & Intellectually it was_exciting time to be a research student at the English faculty. & & \\
\hline 25 & She was inexperienced in the protocol of an industrial action. & 5 & $\mathrm{X}$ \\
\hline 26 & A year later, the three years of the contract didn't seem like such_long time. & 7 & \\
\hline 29 & However, she was not going to show the excessive respect by wearing a formal suit. & $2 *$ & \\
\hline 34 & Her heart swelled with the recognition of _ powerful symbolism of the scene. & $1^{*}$ & $\mathrm{X}$ \\
\hline 35 & The previously unthinkable prospect of_non-academic career now began to be thought. & & \\
\hline
\end{tabular}

Note: NS = Native Speaker; $\#=$ the number of the sentence as it appears in the actual Grammaticality Judgement Task handout; $*=$ frequencies considered as an oversight rather than a real failure to recognize ungrammaticality in subsequent discussion; $\mathrm{X}=$ sentences Alex failed to recognize as ungrammatical.

The Table above contains the 15 ungrammatical sentences which specifically involved the use of articles. As the numbers in the column headed with NS (English native speakers) show, only four (\#\# 7, 13, 15 and 35) out of the 15 sentences $(27 \%)$ were unanimously recognized as ungram- matical by the native speakers controls. Alex's responses overlapped with the native speakers' on three of these four occasions (\#\# 3, 5, and 35). It should perhaps be mentioned that although he did not explicitly recognize sentence \#13 as ungrammatical, he did put a question mark next to the sen- 
tence, suggesting that his intuition was guiding him in a different direction. Unfortunately, he did not indicate what the source of his uncertainty was. The high degree of acceptance by the NS controls of sentences \#\# 3,25 and 26 may be seen as indicating that these sentences are not perceived as a violation of English grammar (contrary to what our two consultants advised after the pilot administration of the grammaticality judgement task). Sentences 9, 10, 12, 19, 23, and 34 were not recognized as ungrammatical only once by the native speaker controls, and sentences 2 and 29 only twice out of possible 8 times. We decided to treat these omissions as an oversight rather than an inability to recognize the ungrammaticality of these sentences. Assuming this to be the case, then Alex's intuitions overlapped with native speakers' on 8 out of the 15 sentences (\#\#3, 7, 10, 12, 15, 25, 26 and 29 ) or $53 \%$ of the time.

\section{DISCUSSION}

As noted earlier, Alex's language samples were collected on two different occasions, almost exactly 24 months apart. From the perspective of fossilization as a local rather than global phenomenon (Han, 2006), we chose to only look at the article use in the subject's interlanguage, not the whole grammatical system. What we found in the language sample is consistent with L2 fossilization-certainly as far as the article system is concerned: article errors are pervasive in both transcripts, first language transfer is very likely a contributing factor, use of the article fluctuates between correct and incorrect usage, and the relative amount of article errors at $\mathrm{T} 2$ exceeds the amount of article errors at T1 (which could be interpreted as backsliding).

The second component of the study, the grammaticality judgement (GJ) task, was designed to establish whether Alex's fluctuating use of the English articles is a feature of competence or performance deficiencies: in the case of the latter, Alex's intuitions about the grammaticality of the sentences in the task would have been the same, or very similar to, the intuitions of the NS controls. However, as the data presented in Table $\mathbf{2}$ show, Alex's judgements coincided with those of the NS controls on only about half of the sentences, and generally his performance on the task was significantly different from that of the NS controls. This can be seen as evidence that - as far as our subject is concernedAlex's fluctuating use of English articles must be rooted in inadequate competence, and is not a performance phenomenon.

In light of the results of our study, the issue of the competence/performance dichotomy warrants some more discussion. The question of what constitutes native speaker competence has rightly held a pivotal place in L2 acquisition theory and in applied linguistics more generally, because it defines the norm according to which L2 attainment is measured, with crucial implications in relation to issues of learnability. In the already substantial body of literature on this, NS ability is commonly conceptualized in terms of the linguistic competence originally proposed by Chomsky: in other words, as a fixed set of representational features (for more on the issue of NS ability see, e.g., Davies, 2003, and Han, 2004a, among many others). Chomsky's 'competence' is a theoretical construct referring to the speaker's idealized unconscious mental knowledge of the grammatical system of the language, which is perfect in the sense that it contains no erroneous or superfluous elements. It is to be differentiated from the actual use of language (the performance), which is imperfect in the sense that it can (and does) contain (sometimes plenty of) performance flaws, such as hesitations, false starts, repetitions, incomplete sentences, etc.

The imperfect nature of the performance presumably disqualifies it as a reliable source of evidence about the properties of the underlying competence: from an innatist perspective, the only way to tap into a speaker's linguistic competence is through his/her intuitive unconscious ability to distinguish between grammatical and ungrammatical sentences, i.e., by asking the individual to provide judgements on the (un)grammaticality of a range of sentences. Proponents of the competence/performance dichotomy treat NS intuitions as a perfect reflection of a perfect internalized linguistic competence: put differently, speakers should unfailingly recognize ungrammatical sentences whenever they see them. Also, within this approach speakers of the same variety of language should have identical intuitions about the grammaticality of different sentences, and that should be reflected in a thoroughly uniform performance on GJ tasks.

While it would be unreasonable to deny its usefulness to linguistic theory, the competence/performance dichotomy should nevertheless be treated with some caution. Our view is that it has led to a rather mechanistic division between competence and performance-very much as if they represent two distinctly different objects of inquiry, rather than two essentially inseparable aspects of the same phenomenon. One very regrettable consequence of this has been that the purely processing aspect of language use has largely been ignored (especially in theoretical linguistics and nativist second language acquisition theories). In addition, the number of failures to recognize ungrammatical sentences on the part of our native speaker controls suggests that the capacity of GJ tasks to yield pure intuitions about grammatical structure may be overrated. There seems to be a very wide, albeit tacit, agreement that performance equals production, which is why performance deficiencies/flaws are almost invariably illustrated with the productive use of language. It is, however, undeniable that the perceptive use of language also has a processing dimension and in that regard language perception can, and should, be treated as a type of performance and thus subject to performance flaws. Indeed, speakers can easily misperceive various aspects of language input because of imperfect hearing, lack of concentration, external distractions, etc. Similar constraints can affect performance on GJ tasks which are essentially a form of language perception. The sentences in a GJ task must be processed before the speaker's intuitions about their respective grammaticality can be evoked, and as a consequence the capacity of a GJ task to evoke intuitions would - at least in part-be a function of processing constraints.

The data derived through the GJ task seem to provide solid support for this assumption. As Table $\mathbf{2}$ above shows, there isn't complete agreement among native speakers in relation to what is grammatical and what is not: this is certainly the case in relation to sentences \#\# 3, 25 and 26, which the bulk of our NS found to be acceptable in contradiction to our expert consultants' determination. Of the remaining 12 unequivocally ungrammatical sentences, eight failed to be 
recognized as ungrammatical on ten different occasions, or $10.4 \%$ of the time. It might be very hard to account for such a relatively high rate of failure to recognize ungrammatical sentences unless we see it as a consequence of processing constraints.

\section{CONCLUSION}

The present research established empirically a case study of a fossilized L2 learner, identified the article as a fluctuating structure in the participant's interlanguage and based on two types of data - the participant's naturalistic (longitudinal) production and performance on a grammaticality judgment task - attempted to determine whether the fluctuation occurred as a function of deficiency in competence or performance. We began the investigation with the assumption that fossilization is a performance phenomenon driven by processing deficiencies. However, the mismatch between the L2 learner's and eight native English speakers' intuitions on the grammaticality judgements led us to believe that fossilization is most likely a competence phenomenon.

Importantly, our NS controls' performance on the GJ task also reinforces the idea that natural languages are dynamic systems, and that the conceptualization of competence as a fixed static end-state condition comprising a set of internalized representational linguistic features may be wrong (Larsen-Freeman, 2006).

How else, then, should linguistic competence be conceptualized? The view we take is that native speaker ability probably involves more than linguistic competence in the Chomskyan sense: in addition to purely formal representational features NS ability also probably involves a specification of processing procedures, i.e., procedures assigning morphosyntactic structure to conceptual and propositional content. Put differently, the processing capacity to produce-spontaneously and effortlessly-unplanned discourse should perhaps be regarded as an essential component of NS ability.

Within such a view, even if the fluctuating performance between correct and incorrect use of the same structure associated with fossilization is taken to be the effect of language processing deficiencies, it would still remain a competence phenomenon.

\section{CONFLICT OF INTEREST}

The authors confirm that this article content has no conflict of interest.

\section{ACKNOWLEDGEMENTS}

Declared none.

\section{APPENDIX}

\section{Grammaticality Judgement Task}

Please consider the following sentences: some of them are grammatically accurate, while the others may contain an error. With regard to each of the sentences below, please select one of the two options (grammatical or ungrammatical) from the drop-down menu on the right. If you select the ungrammatical option, please provide what you believe to be the grammatical version of the sentence in the field below.

Please note that there would at most be one error per sentence. Please ignore punctuation errors (if you come across any).

\section{Example}

\begin{tabular}{|l|l|}
\hline $\begin{array}{l}\text { Her original plan for the previous Wednesday has } \\
\text { been to go to the movies rather than visit the } \\
\text { factory. }\end{array}$ & \begin{tabular}{|l|} 
Ungrammatical \pm \\
grammatical \\
ungrammatical
\end{tabular} \\
\hline $\begin{array}{l}\text { She was tempted to use the weather as an excuse } \\
\text { to cancel the visit. }\end{array}$ & grammatical \\
\hline
\end{tabular}

\section{List of Sentences}

\begin{tabular}{|c|c|}
\hline 1. It was a rare sensation for Robyn. & grammatical \\
\hline $\begin{array}{l}\text { 2. Taking a leave seemed in theory appropriate at this } \\
\text { point. }\end{array}$ & grammatical \\
\hline 3. She knew that cancellation would look bad. & grammatical \\
\hline $\begin{array}{l}\text { 4. I drive every day past the University on my way to } \\
\text { work. }\end{array}$ & grammatical \\
\hline $\begin{array}{l}\text { 5. She awoke on the morning of her job interview with } \\
\text { a heavy heart. }\end{array}$ & grammatical \\
\hline $\begin{array}{l}\text { 6. She couldn't abandon the work ethic that had carried } \\
\text { her successfully through so many years of study. }\end{array}$ & grammatical \\
\hline $\begin{array}{l}\text { 7. She thought that the orange dress was too bright and } \\
\text { might lack the dignity. }\end{array}$ & grammatical \\
\hline $\begin{array}{l}\text { 8. The man who rose from behind the large polished } \\
\text { desk was smaller then she expects. }\end{array}$ & grammatical \\
\hline $\begin{array}{l}\text { 9. What did a liberated woman wear on a visit to } \\
\text { factory? }\end{array}$ & grammatical \\
\hline $\begin{array}{l}\text { 10. With street directory open on the seat beside her, she } \\
\text { set off to find Albert's new house. }\end{array}$ & grammatical \\
\hline $\begin{array}{l}\text { 11. It seemed to her that the relationship had reached a } \\
\text { dead end. }\end{array}$ & grammatical \\
\hline $\begin{array}{l}\text { 12. A thin layer of frost already covered _ hardened } \\
\text { ground. }\end{array}$ & grammatical \\
\hline $\begin{array}{l}\text { 13. She had forgotten how nice it was, after so long } \\
\text { interval. }\end{array}$ & grammatical \\
\hline 14. It seemed that they fulfilled a mutual need. & grammatical \\
\hline $\begin{array}{l}\text { 15. Intellectually it was exciting time to be a research } \\
\text { student at the English faculty. }\end{array}$ & grammatical \\
\hline $\begin{array}{l}\text { 16. Components were stacked in piles all over the } \\
\text { factory floor like the contents of an attic. }\end{array}$ & grammatical \\
\hline $\begin{array}{l}\text { 17. New ideas were imported from Paris by the more } \\
\text { adventurous young lecturers. }\end{array}$ & grammatical \\
\hline $\begin{array}{l}\text { 18. The whole thing seemed designed to produce nothing } \\
\text { but misery for the workers. }\end{array}$ & grammatical \\
\hline
\end{tabular}




\section{(List of Sentences) contd....}

19. The more conservative lecturers viewed these ideas with an alarm, seeing them as a threat to traditional values.

20. It was the most terrible place she had ever been in, in her entire life.

21. Wednesdays she usually spent at home, catching up on her marking.

22. I was usually having lunch at the factory canteen before they closed it.

23. The key would not turn in frozen door lock. grammatical

24. She couldn't imagine herself working in an office or a bank.

grammatical

25. She was inexperienced in the protocol of an industrial action.

grammatical

26. A year later, the three years of the contract didn't seem like such long time.

27. The future of her career was a constant source of concern.

grammatical grammatical

28. There seemed to be no logic or direction to the factory's activities.

29. However, she was not going to show the excessive respect by wearing a formal suit.

30. He was like a schoolboy whose clothes were been purchased to last him forever.

31. 'It was only a one-day strike,' she said at length. 'More of a demonstration, really ...'

grammatical

32. It was rumoured that the number of staff who had responded at the initiative was disappointingly small.

33. Robyn's mental image of a modern factory had derived mainly from TV commercials and documentaries.

34. Her heart swelled with the recognition of powerful symbolism of the scene.

35. The previously unthinkable prospect of nonacademic career now began to be thought.

\section{REFERENCES}

Bosman, E.A., and Charness, N. (1992). Age-related differences in skilled performance and skill acquisition. In: F. Blanchard-Fields and T.
M. Hess (Eds.) Perspectives on Cognitive Change in Adulthood and Aging, (pp. 429-453). New York: McGraw-Hill.

Carroll, S. (2001). Input and Evidence: The Raw Material of Language Acquisition. Amsterdam: John Benjamins.

Davies, A. (2003). The Native Speaker: Myth and Reality. Clevedon: Multilingual Matters.

Denney, N.W. (1990). "Adult age differences in traditional and practical problem solving. In: E.A. Lovelace (Ed.), Aging and Cognition. Mental Processes, Self-Awareness and Interventions, (pp. 329349). Amsterdam: North Holland.

Douglas, D., L. Selinker. (1985). "Principles of Language Tests within the 'Discourse Domain' Theory of Interlanguage: Research, Test Construction and Interpretation." Language Testing, 2, 205-26.

Eckman, F. (1977). Markedness and the contrastive analysis hypothesis. Language Learning, 27, 315-30.

Ellis, R. (1994). The Study of Second Language Acquisition. OUP: Oxford.

Fidler, A. (2006). "Reconceptualizing Fossilization in Second Language Acquisition: A Review [Review Article]." Second Language Research, 22(3), 398-411.

Gass, S. (1997). Input, Interaction, and the Second Language Learner. New Jersey: MahWah, Erlbaum.

Han, Z.H. (1998). "Fossilization: An Investigation into Advanced L2 Learning of a Typologically Distant Language." PhD diss, University of London, London.

Han, Z.H. (2000). "Persistence of the Implicit Influence of the NL: the Case of the Pseudo-Passive. Applied Linguistics, 21(1), 55-82.

Han, Z.H. (2004). To Be a Native Speaker Means Not to Be a Nonnative Speaker. Second Language Research, 20(2), 166-87.

Han, Z.H. (2004). "Fossilization: Five Central Issues." International Journal of Applied Linguistics, 14(2), 212-42.

Han, Z.H. (2006). "Fossilization: Can Grammaticality Judgment Be a Reliable Source of Evidence?" In: Z.H. Han and T. Odlin (Ed.) Studies in Fossilization in Second Language Acquisition, (pp. 5682).

Han, Z.H. (2013). "Forty Years Later: Updating the Fossilization Hypothesis." Language Teaching, 46(2), 133-71.

Lardiere, D. (1998). "Dissociating Morphology from Syntax in a Divergent L2 End-State Grammar." Second Language Research, 14, 359-75.

Lardiere, D. (2000). "Mapping Features to Forms in Second Language Acquisition." In: J. Archibald, Second Language Acquisition and Linguistic Theory, (pp. 102-129). Malden, MA: Blackwell.

Larsen-Freeman, D. (2006). "Second Language Acquisition and the Issue of Fossilization: There is No End, and There is No State." In Studies in Fossilization in Second Language Acquisition, edited by Z.-H. Han and T. Odlin, (pp.189-200). Multilingual Matters.

Long, M.H. (1997). "Fossilization: Rigor Mortis in Living Linguistic Systems? Plenary address to the EUROSLA 97 conference. May 22-4. Universitat Pompeu Fabra, Barcelona.

Long, M. H. (2003). "Stabilization and Fossilization in Interlanguage Development." In The Handbook of Second Language Acquisition, edited by C. J. Doughty and M. H. Long, (pp. 487-536). Blackwell.

Nemser, W. (1971). Approximative Systems of Foreign Language Learners. International Journal of Applied Linguistics, 92, 115-123.

Selinker, L. (1972). Interlanguage. International Review of Applied Linguistics, 10, 209-230.

Selinker, L. (1991). Rediscovering Interlanguage. New York: Longman.

Selinker, L. and J.T. Lamendella. (1978). Two Perspectives on Fossilization in Interlanguage Learning. Interlanguage Studies Bulletin, 3(2), 143-91.

Todeva, E. (1992). On Fossilization in SLA Theory. In Proceedings of the Twelfth Second Language Research Forum, D. Staub and C. Delk, (pp. 216-254). East Lancing: Center for International Programs, Michigan State University.

Received: April 14, 2014

Revised: August 26, 2014

Accepted: September 05, 2014

(C) Moskovsky and Ratcheva; Licensee Bentham Open.

This is an open access article licensed under the terms of the Creative Commons Attribution Non-Commercial License (http://creativecommons.org/licenses/by-nc/3.0/) which permits unrestricted, non-commercial use, distribution and reproduction in any medium, provided the work is properly cited. 